\title{
Association between markers of emphysema and more severe chronic obstructive pulmonary disease
}

\author{
P Boschetto, S Quintavalle, E Zeni, S Leprotti, A Potena, L Ballerin, A Papi, G Palladini, \\ M Luisetti, L Annovazzi, P ladarola, E De Rosa, L M Fabbri, C E Mapp
}

See end of article for authors' affiliations

\section{.................. \\ Correspondence to:} Dr P Boschetto

Dipartimento di Medicina Clinica e Sperimentale, Sezione di lgiene e Medicina del Lavoro, Via Fossato di Mortara 64/b 44100 Ferrara, Italy; bsp@unife.it

Received 2 January 2006 Accepted 29 May 2006

Published Online First

12 June 2006
Background: The predominant emphysema phenotype is associated with more severe airflow limitation in patients with chronic obstructive pulmonary disease (COPD). A study was undertaken to investigate whether COPD patients, with or without emphysema quantitatively confirmed by high resolution computed tomography (HRCT), have different COPD severity as assessed by the BODE index (body mass index, airflow obstruction, dyspnoea, exercise performance) and inspiratory capacity to total lung capacity ratio $(\mathrm{IC} / \mathrm{TLC})$, and by different biological markers of lung parenchymal destruction.

Methods: Twenty six outpatients with COPD and eight healthy non-smokers were examined. Each subject underwent HRCT scanning, pulmonary function tests, cell counts, and measurements of neutrophil elastase, matrix metalloproteinase (MMP)-9 and tissue inhibitor of metalloproteinase (TIMP)- 1 in induced sputum, as well as measurement of desmosine, a marker of elastin degradation in urine, plasma and sputum.

Results: Patients with HRCT confirmed emphysema had a higher BODE index and lower IC/TLC ratio than subjects without $\mathrm{HRCT}$ confirmed emphysema and controls. Forced expiratory volume in 1 second $\left(\mathrm{FEV}_{1}\right)$, $\mathrm{FEV}_{1} /$ forced vital capacity ratio, and carbon monoxide transfer coefficient were lower, whereas the number of eosinophils, MMP-9, and the MMP-9/TIMP-1 ratio in sputum were higher in patients with emphysema. In COPD patients the number of sputum eosinophils was the biological variable that correlated positively with the HRCT score of emphysema $(p=0.04)$

Conclusions: These results suggest that COPD associated with HRCT confirmed emphysema is characterised by more severe lung function impairment, more intense airway inflammation and, possibly, more serious systemic dysfunction than COPD not associated with HRCT confirmed emphysema.
C hronic obstructive pulmonary disease (COPD) is characterised by the progressive development of airflow limitation that is not fully reversible. ${ }^{1}$ Chronic airflow limitation may be caused by increased resistance of the small conducting airways and increased compliance of the lung due to emphysema. ${ }^{1}$ We have previously shown that COPD patients with high resolution computed tomography (HRCT) confirmed emphysema have more severe airflow limitation. ${ }^{2}$ We hypothesise that COPD patients with emphysema, as quantitatively assessed by HRCT scanning, may be associated with more severe disease and may be characterised by biological markers of lung parenchymal destruction measurable by non-invasive methods.

The BODE index (body mass index, airflow obstruction, dyspnoea, exercise performance) and the inspiratory capacity to total lung capacity ratio (IC/TLC) have recently been reported to grade the severity of COPD as a systemic and respiratory disease and to predict the outcome in these patients. ${ }^{34}$ The higher the BODE index and the lower the IC/ TLC ratio, the higher is the risk of death from any cause and respiratory causes in subjects with COPD.

No studies have explored the possible relationship between the extent of emphysema and the severity of COPD, including variables such as the BODE index and IC/TLC. In the one study in which it was shown that COPD patients with emphysema have the lowest survival rate, ${ }^{5}$ the diagnosis of emphysema was based on clinical characteristics only. We therefore planned first to quantify the severity and extent of emphysema on HRCT density mask and then to investigate if patients with HRCT confirmed emphysema have a higher BODE index and lower IC/TLC than patients without HRCT confirmed emphysema.
The development of sputum induction and refined methods of sputum examination have provided the opportunity to examine cell and molecular markers involved in the pathogenesis of COPD. ${ }^{6}$ Neutrophil elastase (NE) and matrix metalloproteinase (MMP)-9 have been shown to be implicated in human emphysema, ${ }^{7}$ their principal effect being the destruction of the extracellular matrix, particularly elastin. Desmosine, an elastin derived crosslink amino acid, is a specific marker of elastin degradation. We therefore hypothesised that COPD patients with emphysema may have higher levels of NE and MMP-9 in sputum and desmosine in urine, plasma, and sputum than patients without emphysema. We then investigated which of the biological markers showed the strongest association with the HRCT emphysema score.

\section{METHODS \\ Subjects}

Fifty patients with moderate to severe $\mathrm{COPD}^{1}$ who presented to the outpatient Clinic of Respiratory Diseases of the University Hospital of Ferrara, Italy underwent HRCT scanning of the chest. Emphysema was indicated by a lung area greater than $15 \%$ showing attenuation values lower than -950 Hounsfield units (HU). ${ }^{8}$ Of the 14 patients with COPD

Abbreviations: BODE index, body mass index, airflow obstruction, dyspnoea, exercise performance; COPD, chronic obstructive pulmonary disease; $F E V_{1}$, forced expiratory volume in 1 second; $F R C$, functional residual capacity; FVC, forced vital capacity; $\mathrm{HRCT}$, high resolution computed tomography; IC, inspiratory capacity; $\mathrm{KCO}$, carbon monoxide transfer coefficient; MLD, mean lung density; MMP, matrix metalloproteinase; $\mathrm{NE}$, neutrophil elastase; $\mathrm{PaO}_{2}$, arterial oxygen tension; $\mathrm{PaCO}_{2}$, arterial carbon dioxide tension; $\mathrm{RV}$, residual volume; TIMP, tissue inhibitor of metalloproteinase; TLC, total lung capacity 
who met the criteria for an HRCT diagnosis of emphysema, three did not complete the study (one because of unsuspected lung malignancy and the other two because they refused to continue). The first 15 of the 36 COPD patients without an HRCT diagnosis of emphysema were enrolled in the study. Five patients (two with and three without emphysema) who completed the present study are also part of a group for which the results have been reported elsewhere. ${ }^{2}$ To quantify emphysema in a control group, we also carried out HRCT scans of the chest on eight age matched healthy nonsmokers. Patients were in a clinically stable condition and had been free from acute exacerbations in the 2 months preceding the study. The study was approved by the ethics committee of the University Hospital of Ferrara and all patients gave their written informed consent.

The medical history including history of chronic bronchitis, ${ }^{1}$ pulmonary function tests, induced sputum, and collection of venous blood and morning urine samples were performed for each subject. All patients were non-atopic, skin prick test negative, and had no history of asthma. Three of the 11 COPD patients with emphysema and five of the 15 without emphysema were being treated with low doses of inhaled glucocorticoids. None of the patients reported having taken non-steroidal anti-inflammatory drugs in the month preceding the study. Plasma used for desmosine determination was obtained after centrifuging the blood specimens at $2500 \mathrm{rpm}$ for 10 minutes. Samples were stored at $-20^{\circ} \mathrm{C}$ until use. The BODE index ${ }^{3}$ was determined in COPD patients.

\section{Computed tomography}

A third generation continuous-rotation CT scanner with volume acquisition extendable to 50 seconds (Tomoscan SR7000, Philips, Einthoven, The Netherlands) was used. The quantitative evaluation of emphysema was based on 1015 slices of $1.5 \mathrm{~mm}$ thick sections acquired with $175 \mathrm{~mA}$ tube current and 2 seconds scanning time, obtained at $2 \mathrm{~cm}$ interval levels from the apex through the base of the lung while the subject was breath holding at full inspiration. For each lung at each level, the total area, the emphysematous area less than $-950 \mathrm{HU}$, and the mean lung density (MLD) were assessed with standard CT software (Hitachi Medical Corporation). At each level the percentage of emphysematous lung was calculated. ${ }^{89}$ The overall degree of emphysema for each subject was expressed as a percentage of the total lung area assessed.

\section{Pulmonary function studies}

In each subject, lung volumes both before and after $400 \mu \mathrm{g}$ inhaled salbutamol (Biomedin, Padova, Italy), the carbon monoxide transfer coefficient (KCO) by the single breath technique, oxygen $\left(\mathrm{PaO}_{2}\right)$ and carbon dioxide $\left(\mathrm{PaCO}_{2}\right)$ tensions of arterial blood (Instrumentations Laboratories, Milan, Italy) were measured as previously described ${ }^{10}$ according to published guidelines. ${ }^{11}{ }^{12}$

\section{Sputum cell counts and mediator measurements}

Sputum was induced and processed in all subjects as previously reported..$^{10} 13$ Increasing concentrations of hypertonic saline were nebulised with an ultrasonic nebuliser (Mistogen Equipment, Oakland, CA, USA). Sputum supernatant was stored at $-80^{\circ} \mathrm{C}$ for later assays and the total protein content was evaluated by the Lowry method. ${ }^{14}$

The MMP-9 activity was detected by zymography as previously described; ${ }^{15}$ the gels were analysed by GS 710 Densitomer (Bio-Rad). This assay measures both pro (latent) form (92 kDa) of MMP-9 and active MMP-9 form (80$88 \mathrm{kDa})$, but is insensitive to proteinase inhibitor complexes. In our samples only the pro MMP-9 was present; no active form was noted in any lane. The lower detection limit of the assay was $2.5 \mathrm{ng} / \mathrm{ml}$, with a within-batch coefficient of variation of $15 \%$. The content of pro MMP-9 free and complexed with TIMP-1, and of total TIMP-1 free and complexed with metalloproteinases, was assessed by ELISA assay (Amersham Pharmacia Biotech). ${ }^{16}$ The sensitivity was $0.6 \mathrm{ng} / \mathrm{ml}$ and $1.25 \mathrm{ng} / \mathrm{ml}$ for MMP-9 and TIMP-1, respectively. The within-batch coefficients of variation for MMP-9 and TIMP- 1 were $0.1 \%$ and $1 \%$ and the between-batch variations were $0.5 \%$ and $1.36 \%$, respectively.

NE activity in sputum was determined by the micellar electrokinetic chromatography method using the synthetic substrate SucAla $_{3}$ NA, as previously described. ${ }^{17}$ The lower detection limit of the method was $0.5 \mathrm{mU} / \mathrm{ml}$ with a within and between-batch coefficient of variation of $1 \%$.

Desmosines (resulting from the sum of the desmosine + isodesmosine levels) were determined in urine and plasma by capillary electrophoresis coupled with laser induced fluorescence, as previously described..$^{19} 19$ The limit of detection of the method was $10^{-8} \mathrm{M}$ (equivalent to $0.1 \mathrm{fmol}$ on column), with a within and between-batch coefficient of variation of $2.5 \%$ and $3.5 \%$, respectively.

To determine the concentration of desmosines in sputum, $200 \mu \mathrm{l}$ of supernatant were deproteinised by addition of $0.45 \mathrm{M}$ trichloroacetic acid $(50 \mu \mathrm{l})$. The pellet obtained upon centrifugation for 10 minutes at $14000 \mathrm{rpm}$ was discarded; desmosine-containing soluble peptides included in the supernatant were transferred to pyrex tubes, evaporated to dryness in vacuo, and hydrolysed by refluxing with $200 \mu \mathrm{l}$ twice distilled constant boiling $6 \mathrm{M} \mathrm{HCl}$ at $106^{\circ} \mathrm{C}$ for 24 hours. The hydrolysed material was dried under a nitrogen stream and the residue was washed four times with deionised water and neutralised with $0.5 \mathrm{M} \mathrm{Na}_{2} \mathrm{CO}_{3}, \mathrm{pH} 8.7$, to give a final volume of $200 \mu \mathrm{l}$. After centrifuging for 15 minutes at $13000 \mathrm{rpm}$, the supernatant was derivatised with fluorescein isothiocyanate (FITC) and analysed on capillary electrophoresis following the same procedure described for urine and plasma. $^{18}{ }^{19}$ Each sample was analysed in triplicate. The yield of derivatisation and the recovery of material were practically identical to those previously indicated for plasma. ${ }^{18}$ Although the number of sputum samples so far analysed was limited, the within and between-batch coefficients of variation were similar to those indicated for the other specimens.

The presence of severe $\alpha_{1}$-antitrypsin deficiency (AATD) was excluded by laboratory diagnosis including nephelometry, isoelectric focusing, and genotyping on dried blood specimens. $^{20}$

\section{Statistical analysis}

Group data are expressed as mean (SE) or as median (interquartile range) when appropriate. Differences between groups were determined by analysis of variance followed by the unpaired Student's $t$ test for normally distributed data and the Kruskall-Wallis test followed by the Mann-Whitney $\mathrm{U}$ test for not normally distributed. Categorical values were analysed using Fisher's exact test. The correlation between HRCT emphysema score and the clinical, functional, and biological variables was tested by Pearson correlation analysis; continuous variables not normally distributed were $\log$ transformed to achieve normality. ${ }^{21} \mathrm{p}$ values $<0.05$ were considered significant. The calculations were made with Statview for Windows Version 5 (SAS Institute; Cary, NC, USA) and with MedCalc for Windows (by F Schoonjans, Mariakerke, Belgium).

\section{RESULTS}

Based on the HRCT emphysema score, the subjects were divided into two groups: COPD with emphysema (mean (SE) score $27.2(1.8) \%$, range $19.6-35.5 \%)$ and COPD without 

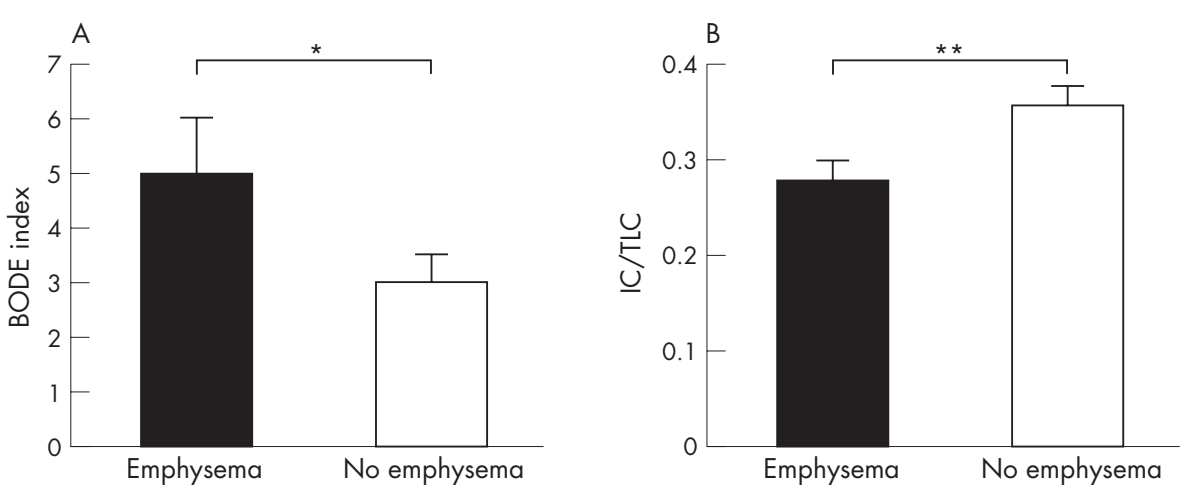

Figure 1 (A) BODE index (body mass index, airflow obstruction, dyspnoea, exercise performance) and (B) IC/TLC (inspiratory capacity/total lung capacity) ratio in patients with chronic obstructive pulmonary disease according to the presence or absence of emphysema on high resolution computed tomographic examination. Data are presented as mean (SE). ${ }^{*} \mathrm{p}=0.02 ;{ }^{* *} \mathrm{p}=0.004$.

emphysema (mean (SE) score $4.7(0.8) \%$, range $1.3-13.2 \%)$. The mean (SE) HRCT score in age matched healthy nonsmokers was $2.4(0.7) \%$ (range $1.3-5.8 \%$ ), and was not different from that of the COPD subjects without emphysema. The mean (SE) MLD in patients with and without emphysema and in controls was -886.1 (8.3) HU, -854.9 (4.7) $\mathrm{HU}$, and -850.6 (11.5) HU, respectively ( $\mathrm{p}=0.004$ in patients with emphysema versus the other two groups).

There was no significant difference in smoking history between COPD patients with emphysema and those with no emphysema (mean (SE) 49 (10) and 33 (7) pack-years, respectively). All patients were ex-smokers except two current smokers in the group with no emphysema.

COPD patients with emphysema had a higher BODE index and lower IC/TLC ratio (fig 1). They had a lower body mass index (BMI), lower $\mathrm{FEV}_{1} \%$ predicted, more dyspnoea according to the modified Medical Research Council (MMRC) scale ${ }^{22}$ than patients with no emphysema, and both groups walked a similar distance in 6 minutes (table 1).

Emphysema patients had a lower $\mathrm{FEV}_{\mathrm{l}} /$ forced vital capacity (FVC) ratio (\%) and KCo (\% predicted) than patients with no emphysema. For similar values of total lung capacity (TLC) in the two groups, functional residual capacity (FRC, \% predicted) and residual volume (RV, \% predicted) were significantly higher in COPD patients with emphysema (table 1). Conversely, the two groups of patients had similar levels of arterial blood gases (table 1) and a similar response to inhaled bronchodilator-that is, a change in $\mathrm{FEV}_{1}$ less than $200 \mathrm{ml}$ and $12 \%$ baseline/predicted. Two of the 11 patients with emphysema and six of the 15 without emphysema had symptoms of chronic bronchitis.

All the studied subjects were able to produce sputum except one emphysematous patient. Patients with emphysema had more sputum eosinophils and fewer sputum macrophages (table 2). They had a higher MMP-9 concentration and MMP-9/TIMP-1 ratio than COPD patients without emphysema (table 3 ) and healthy non-smokers (median (interquartile range) $91.4(39.6-153.6) \mathrm{ng} / \mathrm{ml}, \mathrm{p}=0.01$ and 4.3 (1.8-22.9), p=0.01). Both groups of COPD patients had higher MMP-9 activity (median (interquartile range) 6.1 (4.2-7.9) and 5.7 (3.7-7.4) optical density (OD) $\times \mathrm{mm}^{2} /$ protein $\mathrm{mg} / \mathrm{ml}$ for those with emphysema and no emphysema, respectively) than control subjects (3 (1.6-3.5) OD $\times$ $\mathrm{mm}^{2} /$ protein $\mathrm{mg} / \mathrm{ml} ; \mathrm{p}=0.003$ and $\mathrm{p}=0.01$, respectively).

Free NE activity was detected in five of the 10 sputum samples from COPD patients with emphysema, in two of the 15 samples from COPD patients without emphysema, and in one of the eight healthy non-smokers (data not shown).

Given our familiarity with capillary electrophoresis, we chose this method for measuring the concentration of desmosines in sputum although the technique has not previously been used to measure the cited crosslinks in this matrix. Interestingly, the values obtained, although somewhat lower, were in good agreement with those reported by Ma et $a^{23}$ in five patients with COPD using mass spectrometry. Thus, based on our results, the levels of these specific

Table 1 Characteristics of patients with COPD according to the presence or absence of emphysema on HRCT examination

\begin{tabular}{llll}
\hline & $\begin{array}{l}\text { Emphysema } \\
(\mathbf{n}=11)\end{array}$ & $\begin{array}{l}\text { No emphysema } \\
(\mathbf{n}=15)\end{array}$ & p value \\
\hline Age (years) & $71(3)$ & $70(2)$ & $\mathrm{NS}$ \\
$\mathrm{Sex}(\mathrm{M} / \mathrm{F})$ & $10 / 1$ & $12 / 3$ & \\
$\mathrm{BMI}\left(\mathrm{kg} / \mathrm{m}^{2}\right)$ & $24.5(1.2)$ & $28.1(0.6)$ & 0.008 \\
$\mathrm{Dyspnoea}(\mathrm{MMRC}$ score) & $3(0.4)$ & $2(0.2)$ & 0.03 \\
$6 \mathrm{MWD}(\mathrm{m})$ & $357(42)$ & $395(23)$ & $\mathrm{NS}$ \\
$\mathrm{FEV}(\%$ predicted) & $31.3(2.6)$ & $47.1(3.8)$ & 0.004 \\
$\mathrm{FEV} 1 / \mathrm{FVC}(\%)$ & $37.2(1.9)$ & $49.47(2)$ & 0.0002 \\
$\mathrm{FRC}(\%$ predicted) & $139.6(7.0)$ & $112.5(4.3)$ & 0.002 \\
$\mathrm{KcO}(\%$ predicted) & $31.7(5.2)$ & $54.4(4.3)$ & 0.002 \\
$\mathrm{RV}(\%$ predicted) & $152.9(7.9)$ & $131.1(5.8)$ & 0.03 \\
$\mathrm{PaO}_{2}(\mathrm{kPa})$ & $9.7(0.4)$ & $10.2(0.4)$ & $\mathrm{NS}$ \\
$\mathrm{PaCO}_{2}(\mathrm{kPa})$ & $5.6(0.2)$ & $5.2(0.1)$ & $\mathrm{NS}$
\end{tabular}

NS, not significantly different; BMI, body mass index; MMRC, modified Medical Research Council; 6MWD, 6 minute walk distance; $\mathrm{FEV}_{1}$, forced expiratory volume in 1 second; FVC, forced vital capacity; FRC, functional residual capacity; $\mathrm{KcO}$, carbon monoxide transfer coefficient; $\mathrm{RV}$, residual volume; $\mathrm{PaO}_{2}$, arterial oxygen tension; $\mathrm{PaCO}_{2}$, arterial carbon dioxide tension.

Data presented as mean (SE); comparisons made using unpaired $t$ test. 
Table 2 Sputum cell counts in patients with COPD according to the presence or absence of emphysema on HRCT examination

\begin{tabular}{llll}
\hline & $\begin{array}{l}\text { Emphysema } \\
(\mathbf{n}=10)\end{array}$ & $\begin{array}{l}\text { No emphysema } \\
(\mathbf{n}=15)\end{array}$ & p value \\
\hline Total non-squamous cells $\left(\times 10^{3} / \mathrm{mg}\right)$ & $24.4(15.7-29.5)$ & $17.7(12.9-25.5)$ & $\mathrm{NS}$ \\
Macrophages $\left(\times 10^{3} \mathrm{cell} / \mathrm{mg}\right)$ & $1.6(0.9-2.4)$ & $2.7(1.8-4.6)$ & 0.04 \\
Neutrophils $\left(\times 10^{3} \mathrm{cells} / \mathrm{mg}\right)$ & $21.2(13.2-23.8)$ & $13.3(9-21.1)$ & $\mathrm{NS}$ \\
Eosinophils $\left(\times 10^{3} \mathrm{cell} / \mathrm{mg}\right)$ & $0.8(0.3-1.9)$ & $0.2(0-0.6)$ & 0.02 \\
Lymphocytes $\left(\times 10^{3}\right.$ cells $\left./ \mathrm{mg}\right)$ & $0.1(0-0.1)$ & $0(0-0.1)$ & $\mathrm{NS}$ \\
\hline
\end{tabular}

NS, not significantly different.

Data presented as median (interquartile range); comparisons made using Mann-Whitney $U$ test.

crosslinks in sputum, urine, and plasma were found to be similar in patients with and without emphysema (table 3), although they were significantly increased in both groups of patients compared with healthy non-smokers. The median (interquartile range) levels of desmosines in the latter group were 5.3 (3.9-6.0) ng/mg protein for sputum; 25.4 (21.0$33.8) \mu \mathrm{g} / \mathrm{g}$ creatinine for urine; and 18.3 (11.9-21.2) ng/ml for plasma.

None of the patients was affected by AATD, but four patients (two with and two without emphysema) were found to be carrying intermediate AATD-that is, two PI*MS, one $\mathrm{PI}^{\star} \mathrm{MZ}$, and one PI* MR (where R denotes a rare, non-S and non-Z deficiency allele). However, the mean serum levels of $\alpha_{1}$-antitrypsin did not differ between patients with and without emphysema (mean (SE) 169.5 (15.4) and 163.3 (16.7) mg/dl, respectively; normal values $83-199 \mathrm{mg} / \mathrm{dl}$ ).

The correlation analysis involving the 26 COPD patients showed strong associations between the HRCT emphysema score and both the BODE index and the IC/TLC ratio (table 4). Table 4 also shows the significant correlations between the HRCT score and functional parameters. Among the biological markers, the number of sputum eosinophils showed a positive association with the HRCT score (table 4) and also correlated with IC/TLC $(r=-0.401, \mathrm{p}=0.04)$. However, when the patients with and without emphysema were considered separately, no correlation was observed between the HRCT emphysema score and the BODE index, IC/TLC, or sputum parameters.

\section{DISCUSSION}

This study has shown that COPD patients with HRCT confirmed emphysema have a higher BODE index and lower IC/TLC ratio than those without HRCT confirmed emphysema. COPD patients with emphysema had lower $\mathrm{FEV}_{1}$, $\mathrm{FEV}_{\mathrm{l}} / \mathrm{FVC}$, and $\mathrm{KCO}$, higher $\mathrm{FRC}$, an increased number of eosinophils, and an increased MMP-9 concentration and MMP-9/TIMP-1 ratio in induced sputum.
We have previously shown that COPD patients with emphysema defined by an HRCT visual score have a higher degree of airflow limitation. In this study we have confirmed these findings using CT scanning with a density mask which gives an objective, non-invasive, quantitative method for diagnosing and quantifying emphysema in vivo. ${ }^{24}$

Our findings of a combination of functional measurements reflecting a decrease in maximum flow, a degree of lung hyperinflation, and a decrease in KCO in patients with HRCT confirmed emphysema are in agreement with the results of a recent study that focused on the relationship between the severity and extent of emphysema assessed by HRCT scanning and lung function data. ${ }^{25}$ In addition we found that, in COPD patients, abnormal pulmonary function parameters characteristic of emphysema- $\mathrm{FEV}_{1}, \mathrm{FEV}_{\mathrm{l}} / \mathrm{FVC}$, KCO, and FRCcorrelate with the BODE index and IC/TLC (data not shown), supporting the hypothesis that the emphysema phenotype is associated with more severe disease.

The body mass index was significantly lower and the score on the MMRC dyspnoea scale was significantly higher in patients with emphysema than in those without emphysema. Furthermore, these BODE variables correlate with the HRCT emphysema score, suggesting a more important systemic involvement in emphysematous patients. In these subjects the 6 minute walk distance (6MWT) was lower, but not significantly so, indicating that exercise capacity, as assessed by $6 \mathrm{MWT}$, was slightly impaired in subjects with emphysema compared with those with no emphysema. However, we are aware that formal cardiopulmonary exercise testing should be performed to provide a global evaluation of the exercise capacity. ${ }^{26}$ Further investigations are therefore needed to evaluate a difference in exercise capacity between the two COPD phenotypes.

The most accepted hypothesis for the pathogenesis of emphysema is the proteinase/proteinase inhibitor hypothesis. ${ }^{27}$ In this hypothesis, emphysema develops as a result of an excessive proteinase burden which leads to a proteinase/ proteinase inhibitor imbalance. This study, using induced

Table 3 Levels of biological markers in patients with COPD according to the presence or absence of emphysema on HRCT examination

\begin{tabular}{llll}
\hline Variable* & $\begin{array}{l}\text { Emphysema } \\
(\mathbf{n}=10)\end{array}$ & $\begin{array}{l}\text { No emphysema } \\
(\mathbf{n}=15)\end{array}$ & p value \\
\hline MMP-9 $(\mathrm{ng} / \mathrm{ml})$ & $220.9(175.5-293.3)$ & $72.2(41.9-165.4)$ & 0.04 \\
TIMP-1 $(\mathrm{ng} / \mathrm{ml})$ & $2.3(1.4-19.7)$ & $7.5(4.5-12.7)$ & $\mathrm{NS}$ \\
MMP-9/TIMP-1 ratio & $58.7(20.1-171.5)$ & $7.6(4.3-28.2)$ & 0.01 \\
MMP-9 activity (OD $\times \mathrm{mm}^{2} /$ protein $\left.\mathrm{mg} / \mathrm{ml}\right)$ & $6.1(4.2-7.9)$ & $5.7(3.7-7.4)$ & $\mathrm{NS}$ \\
$\mathrm{NE}$ activity $(\mathrm{U} / \mathrm{ml})$ & $0.01(0-0.29)$ & $0(0-0)$ & $\mathrm{NS}$ \\
Desmosines $(\mathrm{ng} / \mathrm{mg}$ protein) & $12.2(8.0-13.1)$ & $6.3(5.8-13.0)$ & $\mathrm{NS}$ \\
Urinary desmosines $(\mu \mathrm{g} / \mathrm{g}$ creatinine) & $55.8(37.7-74.3)$ & $38.7(34.3-54.9)$ & $\mathrm{NS}$ \\
Plasma desmosines $(\mathrm{ng} / \mathrm{ml})$ & $40.0(22.8-57.0)$ & $29.5(20.5-40.9)$ & $\mathrm{NS}$ \\
\hline
\end{tabular}

MMP-9, matrix metalloproteinase-9; TIMP-1, tissue inhibitor metalloproteinase-1; NS, not significantly different; $\mathrm{OD}$, optical density; NE, neutrophil elastase.

*Variables measured in sputum except where indicated otherwise.

Data are presented as median (interquartile range); comparisons made using Mann-Whitney $\mathrm{U}$ test. 
Table 4 Significant relationships between HRCT emphysema score* and clinical and biological variables in patients with COPD

\begin{tabular}{lrl}
\hline & r value & p value \\
\hline Clinical variables & & \\
BODE index & 0.589 & 0.008 \\
BMl (kg/m $\left.{ }^{2}\right)$ & -0.525 & 0.006 \\
Dyspnoea (MMRC score) & 0.581 & 0.004 \\
IC/TLC & -0.557 & 0.003 \\
FEV $_{1}(\%$ predicted) & -0.480 & 0.013 \\
FEV $1 /$ FVC (\%) & -0.659 & 0.0003 \\
FRC $(\%$ predicted) & 0.587 & 0.002 \\
KCO $\%$ predicted) & -0.615 & 0.0008 \\
RV $(\%$ predicted) & 0.414 & 0.03 \\
Biological variables & \\
Eosinophils $\left(\times 10^{3}\right.$ cells $\left./ \mathrm{mg}\right) \dagger$ & 0.409 & 0.04 \\
\hline
\end{tabular}

$B O D E$, body mass index, airflow obstruction, dyspnoea, exercise performance; BMI, body mass index; MMRC, modified Medical Research

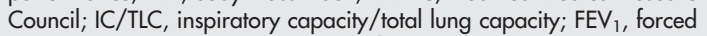
expiratory volume in 1 second; FVC, forced vital capacity; FRC,

functional residual capacity; KCO, carbon monoxide transfer coefficient; RV, residual volume.

*Range 1.3-35.5\%. †Log transformed value.

sputum, showed a significant increase in MMP-9 concentration and MMP-9/TIMP-1 ratio in COPD patients with emphysema. An increase in bronchoalveolar lavage (BAL) fluid concentrations and macrophage expression of MMP-9 (gelatinase B) has been reported in patients with emphysema compared with normal volunteers. ${ }^{28} 29$ Our results, obtained by a non-invasive method such as sputum induction, extend this finding. Indeed, MMP-9 levels and the MMP-9/TIMP-1 ratio were higher in COPD patients with emphysema than in both controls and COPD patients without emphysema, suggesting an amplified protease imbalance in the emphysema phenotype of COPD. There was no difference in MMP-9 activity between the two groups of patients (with or without emphysema). It is likely that the MMP-9 activation occurring in the alveolar compartment macrophages of emphysematous patients could not be measured in induced sputum as the enzyme is rapidly inactivated. There was a positive correlation between MMP-9 activity and the percentage of neutrophils in the COPD patients $(r=0.729, \mathrm{p}<0.0001)$, suggesting that MMP-9 activity in sputum may originate mainly from activated neutrophils which are typically located in the airway lumen of subjects with $\mathrm{COPD}^{30}$ and so are detectable in the sputum. Another possible explanation for the low levels of MMP-9 activity, which was similar in the two groups of patients, is that most of the enzyme present in sputum samples is still in the latent pro-form.

Neutrophil elastase activity and levels of desmosines were similar in the two groups of COPD patients. Although the prominent role of NE in the pathogenesis of emphysema has been known for more than 40 years, ${ }^{31}{ }^{32}$ its association with human emphysema has been inconsistent. ${ }^{7}$ It could be argued that the measurement of elastolytic activity in induced sputum may not accurately assess the activity in the interstitium, the site of extracellular matrix degradation in emphysema. However, the study which showed NE in close association with elastic fibres in the interstitium in an amount that correlates with the severity of emphysema ${ }^{33}$ has been questioned by another study that failed to reproduce these findings. ${ }^{34}$ Furthermore, homogenates of lung removed during volume reduction surgery revealed a significant increase in MMP-9 with no significant increase in NE. ${ }^{35}$ In our patients, only negligible levels of unopposed NE activity could be detected. It is therefore likely that, in these stable patients, NE was efficiently and almost totally inhibited by naturally occurring inhibitors such as $\alpha_{1}$-antitrypsin and
SLPI. In fact, excess free elastase activity can be detected at high levels in lung secretions, particularly during acute bacterial exacerbations. ${ }^{36}$

Desmosine, an elastin derived crosslinked amino acid, has been shown to be increased in the urine of patients with COPD. ${ }^{37} 38$ Our study confirms and extends these results, demonstrating an increase in desmosines also in induced sputum, a more immediate site of the disease, following the preliminary results obtained in spontaneous sputum by HPLC mass spectrometry. ${ }^{23}$ However, no difference was observed in desmosine concentrations in sputum, urine and plasma between patients with and without emphysema. These findings are in agreement with those reported by Gottlieb et al. ${ }^{39}$ Indeed, they showed that, among smokers with a rapid decline in lung function, there was no difference in desmosine excretion between those with and those without CT evidence of emphysema, suggesting that elastin degradation may occur both in emphysema and in airway disease. In contrast, Cocci and co-workers found a negative correlation between the urinary excretion of desmosine and the extent of emphysema..$^{40}$ They used an ELISA method to quantify urine desmosine levels and studied patients admitted for acute exacerbation or under evaluation for lung transplantation. Differences in the methodology and in the selection of patients might therefore explain these discrepancies. In our patients, desmosine levels in sputum, urine and plasma correlated positively with the HRCT emphysema score when all the studied subjects were considered together. Interestingly, desmosines also correlated negatively with $\mathrm{FEV}_{\mathrm{l}} / \mathrm{FVC}$ and positively with $\mathrm{FRC} \%$ and RV\% (data not shown). These data suggest that desmosine may be a useful biological marker of lung destruction in emphysema, although its role in supporting the diagnosis, monitoring disease progress, and assessing the efficacy of therapeutic interventions needs to be further investigated.

This study showed a significant increase in the number of sputum eosinophils in patients with emphysema. The finding of eosinophilic inflammation in the airways of COPD patients strongly supports the so-called "Dutch hypothesis" - that is, smokers with an allergic diathesis have a greater predisposition to develop severe and chronic airflow obstruction. ${ }^{41}{ }^{42}$ However, our patients were non-atopic and the role of eosinophils in COPD is not well established. There are some reports of increased numbers of eosinophils in the airways, BAL fluid, and induced sputum of patients with stable COPD, while others have found no increase in eosinophil numbers in airway biopsy specimens or BAL fluid. ${ }^{43}{ }^{44}$ We found that the number of sputum eosinophils was higher in COPD patients with emphysema than in those with no emphysema or control subjects, but there was no difference between COPD patients with no emphysema and healthy non-smokers. Furthermore, the number of sputum eosinophils correlated positively with the HRCT emphysema score. Interestingly, in situ hybridisation for lung MMP-9 mRNA in a small group of patients with emphysema showed a correlation with the emphysema histological grade and an eosinophilic source of the protein. ${ }^{45}$ On the other hand, MMP-9 is implicated in the chemotaxis of eosinophils ${ }^{46}$ and MMP-9 levels were increased in our patients with emphysema. Finally, the number of sputum eosinophils significantly correlated with the IC/TLC ratio, thus supporting a possible role of eosinophils in the outcome of COPD.

This study has some limitations. Firstly, we performed a cross sectional study which does not allow us to exclude the weight of COPD progression in our findings. To try to rule out the bias of the different $\mathrm{FEV}_{1}$ between patients with and without emphysema, we compared the emphysema group with a subgroup $(n=11)$ of the patients without emphysema matched for $\mathrm{FEV}_{1}$. The significant differences in the clinical and functional parameters and in the number of sputum 
eosinophils were confirmed (data not shown) despite the smaller number of patients. Secondly, because of the small number of observations, we cannot establish whether the lack of correlation between the HRCT emphysema score and the BODE index, IC/TLC, and sputum parameters when patients with and without emphysema were considered separately was due to the small sample size or to a nonexistent relationship. Nevertheless, the patients with COPD and HRCT confirmed emphysema had (1) a higher BODE index, (2) lower IC/TLC, $\mathrm{FEV}_{1}, \mathrm{FEV}_{1} / \mathrm{FVC}$, and $\mathrm{KCO}$, and (3) a higher number of eosinophils, MMP-9 and MMP-9/TIMP-1 ratio in induced sputum than subjects without HRCT confirmed emphysema.

In conclusion, COPD patients with emphysema have more severe lung function impairment, more intense airway inflammation, and possibly more serious systemic dysfunction than patients without emphysema.

\section{ACKNOWLEDGEMENTS}

The authors thank E Forini for her help in the statistical analysis and O Di Maria and I Ferrarotti for their technical assistance.

\section{Authors' affiliations}

P Boschetto, S Quintavalle, E Zeni, A Papi, E De Rosa, C E Mapp, Department of Experimental and Clinical Medicine, University of Ferrara, Ferrara, Italy

S Leprotti, Department of Surgery, Anesthesiology and Radiology, University of Ferrara, Ferrara, Italy

A Potena, L Ballerin, Section of Respiratory Physiopathology, UniversityHospital of Ferrara, Ferrara, Italy

G Palladini, Department of Internal Medicine, IRCCS San Matteo Hospital, University of Pavia, Pavia, Italy

M Luisetti, Department of Respiratory Diseases, IRCCS San Matteo Hospital, University of Pavia, Pavia, Italy

L Annovazzi, P ladarola, Department of Biochemistry, University of Pavia, Pavia, Italy

L M Fabbri, Department of Medicine, Oncology and Radiology, Section of Respiratory Diseases, University of Modena \& Reggio Emilia, Modena, Italy

Supported by the Italian Ministry of University and Research, ARCA, and Consorzio Ferrararicerche.

Competing interests: none declared.

\section{REFERENCES}

1 Pauwels RA, Buist AS, Calverley PM, et al. Global strategy for the diagnosis, management, and prevention chronic obstructive pulmonary disease. NHLBI/ WHO Global Initiative for Chronic Obstructive Lung Disease (GOLD) Workshop Summary. Am J Respir Crit Care Med 2001;163:1256-76.

2 Boschetto P, Miniati M, Miotto D, et al. Predominant emphysema phenotype in chronic obstructive pulmonary disease patients. Eur Respir J 2003;21:450-4.

3 Celli BR, Cote CG, Marin JM, et al. The body-mass index, airflow obstruction, dyspnea, and exercise capacity index in chronic obstructive pulmonary disease. N Engl J Med 2004;350:1005-12.

4 Casanova C, Cote C, de Torres JP, et al. Inspiratory-to-total lung capacity ratio predicts mortality in patients with chronic obstructive pulmonary disease. Am J Respir Crit Care Med 2005;171:591-7.

5 Burrows B, Bloom JW, Traver GA, et al. The course and prognosis of different forms of chronic airways obstruction in a sample from the general population. N Engl J Med 1987;317:1309-14.

6 Barnes PJ, Shapiro SD, Pauwels RA. Chronic obstructive pulmonary disease: molecular and cellular mechanisms. Eur Respir J 2003;22:672-88.

7 Shapiro SD. Proteinases in chronic obstructive pulmonary disease. Biochem Soc Trans 2002;30:98-102.

8 Gevenois PA, Scillia P, de Maertelaer V, et al. The effects of age, sex, lung size, and hyperinflation on CT lung densitometry. AJR 1996;167:1169-73.

9 Madani A, Keyzer C, Gevenois PA. Quantitative computed tomography assessment of lung structure and function in pulmonary emphysema. Eur Respir J 2001;18:720-30.

10 Siafakas NM, Vermeire P, Pride NB, et al. Optimal assessment and management of chronic obstructive pulmonary disease (COPD). The European Respiratory Society Task Force. Eur Respir J 1995;8:1398-420.

11 Quanjer PH, Tammeling GJ, Cotes JE, et al. Lung volumes and forced ventilatory flows. Report Working Party Standardization of Lung Function Tests, European Community for Steel and Coal. Official Statement of the European Respiratory Society. Eur Respir J Suppl 1993;16:5-40.
12 Cotes JE, Chinn DJ, Quanjer PH, et al. Standardization of the measurement of transfer factor (diffusing capacity). Report Working Party Standardization of Lung Function Tests, European Community for Steel and Coal. Official Statement of the European Respiratory Society. Eur Respir J Suppl 1993;16:41-52.

13 Rytila PH, Lindqvist AE, Laitinen LA. Safety of sputum induction in chronic obstructive pulmonary disease. Eur Respir J 2000;15:1116-9.

14 Lowry OH, Rosebrough NJ, Farr AL, et al. Protein measurement with the folin phenol reagent. J Biol Chem 1951;193:265-75.

15 Kleiner DE, Stetler-Stevenson WG. Quantitative zymography: detection of picogram quantities of gelatinases. Anal Biochem 1994;218:325-9.

16 Vignola AM, Riccobono L, Mirabella A, et al. Sputum metalloproteinase-9/ tissue inhibitor of metalloproteinase-1 ratio correlates with airflow obstruction in asthma and chronic bronchitis. Am J Respir Crit Care Med 1998;158:1945-50.

17 Viglio S, Luisetti M, Zanaboni G, et al. Simultaneous determination of Pseudomonas aeruginosa elastase, human leukocyte elastase and cathepsin $G$ activities by micellar electrokinetic chromatography. J Chromatogr A 1999;846:125-34.

18 Annovazzi L, Viglio S, Perani E, et al. Capillary electrophoresis with laserinduced fluorescence detection as a novel sensitive approach for the analysis of desmosines in real samples. Electrophoresis 2004;25:683-91.

19 Annovazzi L, Viglio S, Gheduzzi D, et al. High levels of desmosines in urine and plasma of patients with pseudoxanthoma elasticum. Eur J Clin Invest 2004;34:156-64.

20 American Thoracic Society/European Respiratory Society. Standards for the diagnosis and management of individuals with alpha-1 antitrypsin deficiency. Am J Respir Crit Care Med 2003;168:818-900.

21 Armitage P, Berry G. Statistical methods in medical research, 3rd ed. Oxford: Blackwell, 1994.

22 Mahler DA, Wells CK. Evaluation of clinical methods for rating dyspnea. Chest 1988;93:580-6.

$23 \mathrm{Ma} \mathrm{S}$, Lieberman S, Turino GM, et al. The detection and quantitation of free desmosine and isodesmosine in human urine and their peptide-bound forms in sputum. Proc Natl Acad Sci USA 2003;100:12941-3.

24 Muller NL, Staples CA, Miller RR, et al. "Density mask". An objective method to quantitate emphysema using computed tomography. Chest 1988;94:782-7.

25 Cerveri I, Dore R, Corsico A, et al. Assessment of emphysema in COPD: a functional and radiologic study. Chest 2004;125:1714-8.

26 American Thoracic Society. ATS statement: guidelines for the six-minute walk test. Am J Respir Crit Care Med 2002;166:111-7.

27 Hogg JC, Senior RM. Chronic obstructive pulmonary disease - 2: Pathology and biochemistry of emphysema. Thorax 2002;57:830-4.

28 Finlay GA, Russell KJ, McMahon KJ, et al. Elevated levels of matrix metalloproteinases in bronchoalveolar lavage fluid of emphysematous patients. Thorax 1997;52:502-6.

29 Finlay GA, O'Driscoll LR, Russell KJ, et al. Matrix metalloproteinase expression and production by alveolar macrophages in emphysema. Am J Respir Crit Care Med 1997; 156:240-7.

30 Saetta M, Turato G, Maestrelli $P$, et al. Cellular and structural bases of chronic obstructive pulmonary disease. Am J Respir Crit Care Med 2001;163:1304-9.

31 Gross P, Pfitzer EA, Tolker E, et al. Experimental emphysema: its production with papain in normal and silicotic rats. Arch Environ Health 1965;11:50-8.

32 Laurell CB, Eriksson S. The electrophoretic alpha 1-globulin pattern of serum in alpha 1-antitrypsin deficiency. Scand J Clin Lab Invest 1963;15:132-40.

33 Damiano VV, Tsang A, Kucich $U$, et al. Immunolocalization of elastase in human emphysematous lungs. J Clin Invest 1986:78:482-93.

34 Fox B, Bull TB, Guz A, et al. Is neutrophil elastase associated with elastic tissue in emphysema? J Clin Pathol 1988;41:435-40.

35 Ohnishi K, Takagi M, Kurokawa Y, et al. Matrix metalloproteinase-mediated extracellular matrix protein degradation in human pulmonary emphysema. Lab Invest 1998;78:1077-87.

36 Hill AT, Campbell EJ, Bayley DL, et al. Evidence for excessive bronchial inflammation during an acute exacerbation of chronic obstructive pulmonary disease in patients with $\alpha_{1}$-antitrypsin deficiency (PiZ). Am J Respir Crit Care Med 1999; 160:1968-75.

37 Stone PJ, Gottlieb DJ, O'Connor GT, et al. Elastin and collagen degradation products in urine of smokers with and without chronic obstructive pulmonary disease. Am J Respir Crit Care Med 1995;151:952-9.

38 Viglio $S$, ladarola $P$, Lupi $A$, et al. MEKC of desmosine and isodesmosine in urine of chronic destructive lung disease patients. Eur Respir J 2000;15:1039-45.

39 Gottlieb DJ, Stone PJ, Sparrow D, et al. Urinary desmosine excretion in smokers with and without rapid decline in lung function: the Normative Aging Study. Am J Respir Crit Care Med 1996;154:1290-5.

40 Cocci $F$, Miniati M, Monti S, et al. Urinary desmosine excretion is inversely correlated with the extent of emphysema in patients with chronic obstructive pulmonary disease. Int J Biochem Cell Biol 2002;34:594-604.

41 Postma DS, Boezen HM. Rationale for the Dutch hypothesis. Chest 2004; 126:96-104S.

42 Jindal SK. Dutch hypothesis. Chest 2004;126:329-30.

43 Turato G, Zuin R, Saetta M. Pathogenesis and pathology of COPD. Respiration 2001;68:117-28.

44 Fujimoto K, Yasuo M, Urushibata K, et al. Airway inflammation during stable and acutely exacerbated chronic obstructive pulmonary disease. Eur Respir J 2005;25:640-6.

45 Rosenbluth DB, Shapiro SD, Hogg JC, et al. Expression of the mRNA for the $92 \mathrm{kD}$ gelatinase is increased in emphysema (abstract). Am J Respir Crit Care Med 1995:151:A529.

46 Okada S, Kita H, George TJ, et al. Migration of eosinophils through basement membrane components in vitro: role of matrix metalloproteinase-9. Am J Respir Cell Mol Biol 1997; 17:519-28. 